\title{
Gender and Age Differences in the Sharing Behavior of Online Video Advertisements: The Case of Selangor, Malaysia
}

\author{
Nik Mohamad Shamim Nik Mohd Zainordin ${ }^{1}$, Norazlyn Kamal Basha ${ }^{1}$, Ho Jo Ann ${ }^{1}$, \& Ng Siew Imm ${ }^{1}$ \\ ${ }^{1}$ School of Business and Economics, Universiti Putra Malaysia, 43400 Serdang, Selangor, Malaysia \\ Correspondence: Norazlyn Kamal Basha. E-mail: norazlyn@upm.edu.my
}

Received: October 5, 2021

Accepted: October 19, 2021

Online Published: November 29, 2021

doi:10.5539/ass.v17n12p49

URL: https://doi.org/10.5539/ass.v17n12p49

\begin{abstract}
Gender and age are considered important demographic factors that influence consumers' behavioral intention, especially pertaining to video advertisements. However, limited research has examined the impact of gender and age on consumers' sharing behavior of online video advertisements (OVAs) in Selangor, Malaysia. The aim of this paper is therefore to examine the role of gender and age in the intention to share OVAs in Selangor. Survey data was collected from 180 Millennial respondents in Selangor and analyzed using t-test and ANOVA to detect gender and age differences in the intention to share OVAs. The results indicated that gender and age have significantly distinct impacts on the intention to share OVAs among Millennials in Selangor. Male Millennials were found have a stronger intention to share OVAs compared to females, whereas Millennials in the 19 to 24 age bracket showed a stronger intention to share OVAs than those in the 25 to 30 and 31 to 38 age brackets. The study's practical implications, limitations, and future research directions are discussed.
\end{abstract}

Keywords: gender, age, behavioral intention, online video advertisements

\section{Introduction}

Due to the Covid-19 pandemic, the usage of online mediums in various aspects of everyday life has become the new normal. In line with this change, businesses are shifting their marketing strategies from traditional media advertising to Internet and social media advertising to promote their products and services. According to Thoo et al. (2018), advertising through social media is more effective than traditional advertising as it can better influence consumers. Statista Portal (2018) further reported that Malaysia's total digital advertising expenditure was MYR1.20 billion in 2018, and is expected to increase due to broad opportunities for the development of online advertising in the country.

Online video advertisements (OVAs) represent one of the fastest-growing platforms of social media advertising. Online video advertising, also termed Internet advertising and digital advertising by Lee et al. (2021), is advertising that uses Internet technologies to publish videos containing information on products and services. One main feature of OVAs that attracts the interest of marketers and advertisers is the ability of viewers to share OVAs across multiple online platforms. If viewers wish to share an advertisement with others, all they need to do is to click on the share button next to the advertisement to post it on their user profile. In Malaysia, $61.8 \%$ of online content is shared, as consumers perceive that such content is beneficial, entertaining, and creates awareness of product or services (Malaysian Communication \& Multimedia Commission, MCMC, 2019). Furthermore, a majority of Malaysians share OVAs with educational (71.8\%) and entertainment $(64.1 \%)$ value on their social media platforms (e.g., Facebook). (MCMC, 2021). MCMC (2021) also stated that most Internet users in Malaysia share OVAs weekly (49.1\%), while some (19.2\%) share them daily. These statistics indicate that the level of online content sharing in Malaysia is relatively high, with at least half of Malaysian Internet users actively engaging in OVA sharing behavior.

However, based on report from CNBC News (2017), 65\% of people skip the online video advertisements. One of the common forms of online advertising format that used by marketers is the "pre-roll advertising," which the advertisement is played before a video, and can be skipped after a certain amount of time. Moreover, $76 \%$ of people mentioned that they skip the online advertisement because it's an ingrained behavior.

Past studies on online advertising have explored the differences in consumers' characteristics (e.g., gender, age, attitude, education level) with regard to their perspectives of online advertising, including attitude towards Facebook advertising (Thoo et al., 2018), advertising on social networking sites (Ahmad et al., 2018), and 
emotional advertising (Kasper, 2020). Conversely, limited studies have concentrated on respondents' demographic differences in their intention to share OVAs.

Thus, this study attempted to explore if there are any differences in the intention to share OVAs by gender and age. Moreover, there is a dearth of research on OVAs in Selangor, Malaysia, even though Selangor records the highest percentage of Internet users among the nation's 14 states (MCMC, 2018). Therefore, the objective of this paper was to examine the role of gender and age in the intention to share OVAs in Selangor.

\section{Literature Review}

\subsection{Intention to Share OVAs}

Ajzen (1991) defined intention as the motivational factor that influences behavior, reflected by an individual's willingness to exert effort in planning and performing the behavior. Therefore, the stronger the intention to engage in a behavior, the more likely its performance. Additionally, certain behavioral intentions result in behavior only if the behavior in question is under volitional control, that is, if the individual can decide at will to perform or not perform the behavior. Intention is expected to influence performance more for an individual who has higher behavioral control, to the extent that the individual is motivated to try.

Numerous studies have evaluated behavioral intention in relation to OVAs. For instance, Choi (2020) examined the impacts of personality traits on OVA sharing intention, revealing that extraversion, neuroticism, and openness to experience are the Big Five personality traits that positively affect OVA sharing intention. Park and Han (2019) further found that the cognitive, emotional, and behavioral effects of mobile video advertising have significant implications for sharing intention. Likewise, Firat's (2019) research investigated the factors that affect YouTube advertising value and its effect on purchasing intention. Notably, the study also examined whether YouTube advertising value factors differ according to demographic variables, finding that: (1) men are more irritated than women about YouTube ads; (2) perceptions of informativeness as well as entertainment and trendiness differ by age group; and (3) irritability, informativeness, and entertainment and trendiness differ by income group.

\subsection{Gender Influence}

Demographic traits have been widely discussed in previous research, among which the most frequently examined are gender, age, level of income, occupation, and marital status. The World Health Organization (WHO) defines gender as two groups of socially constructed personalities (i.e., male and female) which have significant differences in norms and behaviors, observable in their communication, decision making, relative power, and relationships.

Thoo et al. (2018) found significant differences between males' and females' attitudes towards Facebook advertisements based on their distinct usage of the social media platform. Similarly, Smith (2019) revealed gender differences in digital natives' perceptions of mobile advertising, whereby females strongly prefer mobile advertising that allows them to shop directly from the ad while males do not feel as strongly about it despite admitting it is a good idea. Furthermore, Suh, Wilson and On (2021) research on gender differences in visual attention to the digital content of place-based advertising indicated that female shoppers are more likely to respond to gaze cues and to notice place-based advertising if others are also looking at the ad. On the other hand, male shoppers were found to display longer staying and fixation times than females. Based on these arguments on significant gender differences, the current research proposed the following hypothesis:

H1: There is a significant difference in the intention to share OVAs between genders.

\subsection{Age Influence}

Oxford Dictionary defines age as the length of period that an individual has lived or a thing has lasted. Age plays an important role in assessing group-based differences in a particular scenario. Accordingly, substantial research has measured the role of age in advertising. In this regard, the current study explored how three age categories of Millennials in Selangor differentiate their intention to share OVAs.

Veljanova (2018) examined age and gender differences in how emotions are affected by advertising messages at different levels of fear. The findings indicated statistically significant differences in age only between negative emotions and a low-intensity fear appeal. Perju-Mitran and Budacia (2017) also explored age differences in responses to marketing communication techniques used in online social networks. The results revealed that the magnitude of the positive effects of users' perceptions and attitudes towards online marketing communication on their intentions vary across age groups. Other than that, Zvonova, Vakula and Pestereva (2021) demonstrated statistically distinct effects of age characteristics on advertising perception. Therefore, given evidence on the significant differences in age, the current research proposed the following hypothesis: 
H2: There is a significant difference in the intention to share OVAs among the three Millennial age groups

\section{Methodology}

\subsection{Measurement}

The study's questionnaire was divided into two sections: respondents' demographic details and intention to share OVAs. The measurement items for intention to share OVAs were adapted from Lee et al. (2013) and rated on a Likert scale ranging from 1 (strongly disagree) to 7 (strongly agree). Five questions were presented to understand the demographic characteristics of the respondents, namely their gender, age, race, education level, and frequency of watching OVAs. The summary of these details is reported in Table 1 . The respondents of this study comprised 160 Millennials in Selangor. They were approached at four shopping malls (Sunway Piramid, The Mines, Aeon Shah Alam, and Dpulze Cyberjaya) and three universities (Universiti Putra Malaysia, Universiti Kebangsaan Malaysia, and UiTM Shah Alam) and asked to complete the survey in online format via an iPad.

\subsection{Data Analysis}

The collected data was analyzed using the Statistical Package for Social Sciences (SPSS) software. First, descriptive analysis was performed to summarize the respondents' profile. Then, a t-test was run for gender while an ANOVA test was conducted for age to compare means between groups.

\section{Results and Discussion}

\subsection{Profile of Respondents}

As shown in Table 1, out of the 160 respondents, $50 \%$ were male and $50 \%$ were female. The current study focused on Millennials, who can be divided into three age groups, i.e., 19 to 24 years old (61.3\%), 25 to 30 years old $(29.4 \%)$, and 31 to 38 years old $(9.4 \%)$. Based on the results, the younger group of Millennials dominated the study sample. The respondents consisted of 115 Malays, 32 Chinese, 8 Indians, and 5 who identified as 'Other'. Most of the respondents possessed Degree-level education (73.1\%), while the rest had Master's (13.1\%), Diploma, (6.9\%), $\mathrm{PhD}$ (2.5\%), or Secondary School (2.5\%) qualifications.

Respondents were also asked how often they watch OVAs. Surprisingly, most of them watch OVAs everyday $(63.7 \%)$ or once per week (29.4\%), whereas only a few watch OVAs once per month (6.9\%).

Table 1. Profile of respondents

\begin{tabular}{|c|c|c|}
\hline Variable & Frequency & Percent \\
\hline \multicolumn{3}{|l|}{ Gender } \\
\hline Male & 80 & 50.0 \\
\hline Female & 80 & 50.0 \\
\hline \multicolumn{3}{|l|}{ Age } \\
\hline $19-24$ & 98 & 61.3 \\
\hline $25-30$ & 47 & 29.4 \\
\hline $31-38$ & 15 & 9.4 \\
\hline \multicolumn{3}{|l|}{ Race } \\
\hline Malay & 115 & 71.9 \\
\hline Chinese & 32 & 20.0 \\
\hline Indian & 8 & 5.0 \\
\hline Other & 5 & 3.1 \\
\hline \multicolumn{3}{|l|}{ Education Level } \\
\hline Secondary School & 4 & 2.5 \\
\hline Diploma & 11 & 6.9 \\
\hline Degree & 117 & 73.1 \\
\hline Master's & 21 & 13.1 \\
\hline $\mathrm{PhD}$ & 4 & 2.5 \\
\hline Others & 3 & 1.9 \\
\hline \multicolumn{3}{|c|}{ How often do you watch OVAs? } \\
\hline Everyday & 102 & 63.7 \\
\hline Once per Week & 47 & 29.4 \\
\hline Once per Month & 11 & 6.9 \\
\hline
\end{tabular}




\section{2 t-test Results of Gender and the Intention to Share OVAs}

A t-test is used to compare the mean scores of a continuous variable for two different groups of participants (Pallant, 2010). The current study employed the t-test to detect any significant difference between both genders' (males' and females') intention to share OVAs. According to Fisher (1973), the acceptable value of a t-test is a cut-off value (t-value) more than 1.96 and a significance value (p-value) less than 0.05 . According to Table 2 , the results confirmed a significant difference between males' and females' intention to share OVAs $(t=9.422, p=$ 0.000). The mean scores further showed that males (mean $=14.25$ ) have a higher intention to share OVAs compared to females $($ mean $=8.97)$.

Table 2. t-test Results

\begin{tabular}{ccccccccc}
\hline Variable & Gender & $\mathrm{N}$ & Mean & $\mathrm{t}$ & $\mathrm{df}$ & Sig. (2 tailed) & Hypothesis & Results \\
\hline \multirow{2}{*}{ Intention to share OVAs } & Male & 80 & 14.25 & 9.422 & 158 & .000 & H1 & Supported \\
& Female & 80 & 8.97 & & & & & \\
\hline
\end{tabular}

\subsection{ANOVA Results of Age and the Intention to Share OVAs}

The Analysis of Variance or ANOVA is used to compare the mean scores of a continuous variable for more than two different groups of participants (Pallant, 2010). The current study examined Millennials in three age groups: 19 to 24 years old, 25 to 30 years old, and 31 to 38 years old. According to the results of the ANOVA test, the intention to share OVAs differs by Millennials' age category $(\mathrm{F}=101.28, \mathrm{p}=0.000)$. Specifically, respondents in the 19 to 24 years old age group have a greater intention to share OVAs compared to those in the 25 to 30 years old and 31 to 38 years old age groups (refer to Table 3 ).

Table 3. Analysis of Variance (ANOVA)

\begin{tabular}{ccccccccc}
\hline Variable & Age & $\mathrm{N}$ & Mean & Std. Deviation & $\mathrm{F}$ & Sig. & Hypothesis & Results \\
\hline \multirow{3}{*}{ Intention to share OVAs } & $19-24$ & 52 & 16.32 & 2.61 & 101.28 & 0.000 & H2 & Supported \\
& $25-30$ & 53 & 9.88 & 1.84 & & & & \\
& $31-38$ & 55 & 8.81 & 3.90 & & & & \\
\hline
\end{tabular}

\section{Discussion, Implications, Limitations, and Future Research}

\subsection{Discussion}

The objective of this paper was to examine the roles of gender and age in determining Millennials' intention to share OVAs in Selangor. Based on the analysis results, there are significant differences by gender and age in the intention to share OVAs. First, the findings showed that males have a stronger intention to share OVAs compared to females in Selangor (H1 was accepted). This finding is consistent with past research that has reported a significant difference between genders in advertising. Rialti et al. (2017), Parengkuan (2017), and Lin et al. (2019) also found that males are more influenced by advertising. In particular, Lin et al. (2019) explained that males show more positive attitudes and beliefs towards online advertising, which influences their intention to share OVAs; this was proven by the current study as well. As the current study able to prove that gender is playing role in online consumer's behaviour in the context of sharing OVAs which this finding is valuable for marketing researcher to comprehend role of gender in OVAs behaviour. As the current study examined gender perspective in the context of consumer behaviour it is useful to the marketers who use OVAs as their marketing tools. Gender are considered as important factor in market segmentation and based on the finding, marketers can use OVAs as marketing technique to attract male customers.

The second finding of the current study is the significant difference between Millennials' age groups in their intention in share OVAs. The results of the ANOVA analysis indicated that Millennials aged between 19 and 24 years old have a greater intention to share OVAs. This is consistent with the findings of Hall, Towers and Shaw (2017) that Millennials in the 19 to 24 age are incredibly sophisticated, technology savvy, and generally immune to traditional marketing and sales pitches. Since they prefer to spend time on various technologies and the Internet, they are seen as the driving force of online commerce (Ladhari, Gonthier \& Lajante, 2019). This 
justifies that Millennials from 19 to 24 years old are more likely to share OVAs with others on their social media platforms. In marketing technique, attracting right target customers are very important as it can make sure that the marketing effort are successful. The current study able to verify that age become one of the factors that influence the online consumer's behaviour. The suitability of advertising medium must tally with age of target audience. As discovered by the current research, the age of 19 to 24 years old are more influenced with the marketing technique using OVAs.

\subsection{Implications}

The current study has implications for marketing practitioners, who can use its findings to segment their target markets using OVAs. First, based on the significant gender difference found, marketers can create OVAs that are more likely to attract and influence male consumers to watch and share them. Focusing on the male segment can increase the likeability of marketers' OVAs, given that males were found to exhibit a greater intention to share OVAs. Second, with regard to Millennials' age, marketers can release OVAs that appeal to the preferences of consumers aged 19 to 24 , such as by incorporating elements of entertainment, informativeness, and trustworthiness. In conclusion, marketers can influence and attract more people to watch and share OVAs by prioritizing male consumers and Millennials aged 19 to 24 .

\subsection{Limitations and Future Research}

Among the limitations of this study is that it took place solely in the state of Selangor, despite the fact that Malaysia has 14 states that are exposed to the Internet and OVAs. Future research can extend this study to the national context to detect age and gender differences in Malaysians' intention in share OVAs. The second limitation is that this study focused only on two demographic factors, i.e., gender and age, thereby neglecting the consideration of other demographic factors like education level, income level, occupation, and family size. These various factors may potentially play an important role in shaping consumers' intention to share OVAs. Consequently, future research is suggested to include other demographic factors to gain more accurate findings on OVA sharing behavior. Lastly, the sample of this study only comprised Millennials in Selangor aged between 19 and 34 years old. Although the choice of sample was well-justified given the scope of the current study, it would be interesting to extend the study's model to other generational cohorts, especially since all age groups have access to the Internet and are exposed to OVAs in current times. For example, Gen Z and even Baby Boomers have an increasing presence on social media and may have different motivating factors that drive their behavioral intention to share OVAs.

\section{References}

Ahmad, A., Khan, M. N., \& Rahman, O. (2018). Advertising on Social Networking Sites (SNSs): Exploring the Gender Differences. Pacific Business Review International, 11(3), 115-121.

Ajzen, I. (1991). The theory of planned behavior. Organizational behavior and human decision processes, 50(2), 179-211. https://doi.org/10.1016/0749-5978(91)90020-T

Choi, C. W. (2020). The impacts of consumer personality traits on online video ads sharing intention. Journal of Promotion Management, 26(7), 1073-1092. https://doi.org/10.1080/10496491.2020.1746468

CNBC News. (2017). Sixty-five percent of people skip online video ads. Here's what do about it. Retrieved from https://www.cnbc.com

Firat, D. (2019). YouTube advertising value and its effects on purchase intention. Journal of Global Business Insights, 4(2), 141-155.

Fisher, R. (1973). Statistical methods for research workers. New York: Hafner Publishing.

Hall, A., Towers, N., \& Shaw, D. R. (2017). Understanding how millennial shoppers decide what to buy: Digitally connected unseen journeys. International Journal of Retail \& Distribution Management. https://doi.org/10.1108/IJRDM-11-2016-0206

Kasper, R. (2020). Gender Differences in Emotional Advertising: How Types of Emotion Impact One's Trust and Attitude Toward a Brand. ELON JOURNAL, 31.

Ladhari, R., Gonthier, J., \& Lajante, M. (2019). Generation Y and online fashion shopping: Orientations and profiles. Journal of retailing and Consumer Services, 48, 113-121. https://doi.org/10.1016/j.jretconser.2019.02.003

Lee, J., Ham, C. D., \& Kim, M. (2013). Why people pass along online video advertising: From the perspectives of the interpersonal communication motives scale and the theory of reasoned action. Journal of Interactive 
Advertising, 13(1), 1-13. https://doi.org/10.1080/15252019.2013.768048

Lee, S. H., Yoon, S. H., \& Kim, H. W. (2021). Prediction of Online Video Advertising Inventory Based on TV Programs: A Deep Learning Approach. IEEE Access, 9, 22516-22527. https://doi.org/10.1109/ACCESS.2021.3056115

Lin, X., Featherman, M., Brooks, S. L., \& Hajli, N. (2019). Exploring gender differences in online consumer purchase decision making: An online product presentation perspective. Information Systems Frontiers, 21(5), 1187-1201. https://doi.org/10.1007/s10796-018-9831-1

Malaysian Communication and Multimedia Commission. (2018). Department of Statistics Malaysia. Internet User Survey. Retrieved from https://www.mcmc.gov.my

Malaysian Communication and Multimedia Commission. (2019). Department of Statistics Malaysia. Internet User Survey. Retrieved from https://www.mcmc.gov.my

Malaysian Communication and Multimedia Commission. (2021). Department of Statistics Malaysia. Internet User Survey. Retrieved from https://www.mcmc.gov.my

Pallant, J. (2010). SPSS Survival Manual (4th ed.). Allen and Unwin Book Publishers, Australia.

Parengkuan, M. W. (2017). A comparative study between male and female purchase intention toward visual merchandising at centro by parkson department store mantos. Jurnal Berkala Ilmiah Efisiensi, 17(1).

Park, L. M., \& Han, S. (2019). The effectiveness of the process of mobile video advertising-Focused on the perceived intrusiveness and attitude toward advertising. International Journal of Innovative Technology and Exploring Engineering, 8(8), 264-269.

Perju-Mitran, A., \& Budacia, A. E. (2017). Age differences in responses to marketing communication techniques used in online social networks. Journal of Information Systems \& Operations Management, 1, 385-395.

Rialti, R., Zollo, L., Pellegrini, M. M., \& Ciappei, C. (2017). Exploring the antecedents of brand loyalty and electronic word of mouth in social-media-based brand communities: Do gender differences matter? Journal of Global Marketing, 30(3), 147-160. https://doi.org/10.1080/08911762.2017.1306899

Smith, K. T. (2019). Mobile advertising to Digital Natives: Preferences on content, style, personalization, and $\begin{array}{lllll}\text { functionality. Journal of } & \text { Strategic } & \text { Marketing, } & \text { 27(1), }\end{array}$ https://doi.org/10.1080/0965254X.2017.1384043

Statista Portal. (2018). Advertising Expenditure in Malaysia from 2010 until 2018. Retrieved from https://www.statista.com

Suh, T., Wilson, R. T., \& On, S. (2021). Gender difference in visual attention to digital content of place-based advertising: A data-driven scientific approach. Electronic Commerce Research, 1-21.

Thoo, A. C., Ho, P. H., Muharam, F. M., \& Lom, H. S. (2018). Millennials' attitudes toward Facebook advertising. Advanced Science Letters, 24(6), 3864-3868. https://doi.org/10.1166/asl.2018.11499

Veljanova, R. (2018). The Connection Between Advertising Messages with Different Level of Fear and Emotions According to Age and Sex. Knowledge International Journal, 28(1), 223-230. https://doi.org/10.35120/kij2801223

Zvonova, E., Vakula, I., \& Pestereva, N. (2021). Age and Ethnocultural Characteristics of Advertising Perception. American Scientific Journal, 1(46), 21-28. https://doi.org/10.31618/asj.2707-9864.2021.1.46.85

\section{Copyrights}

Copyright for this article is retained by the author(s), with first publication rights granted to the journal.

This is an open-access article distributed under the terms and conditions of the Creative Commons Attribution license (http://creativecommons.org/licenses/by/4.0/). 